\title{
Correction to: Sound reasoning in tock-CSP
}

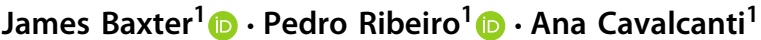 \\ Published online: 15 October 2021 \\ (c) Springer-Verlag GmbH Germany, part of Springer Nature 2021
}

\section{Correction to: Acta Informatica https://doi.org/10.1007/s00236-020-00394-3}

In the original article, there were a few errors published online. These are as follows:

- changing " $r 2 r$ " to " $r 2 \backslash$ prefix $r$ " in Eqs. (21) and (22) on page 14

- replacing "the traces from $P$ that" with "traces based on traces of $P$ that" in the final paragraph on page 16

- changing the type of $r$ to "seq $O b s$ " in Eq. (50) on page 19

The original article has been corrected.

Publisher's Note Springer Nature remains neutral with regard to jurisdictional claims in published maps and institutional affiliations.

The original article can be found online at https://doi.org/10.1007/s00236-020-00394-3.

$凶 \quad$ James Baxter

james.baxter@york.ac.uk

1 Department of Computer Science, University of York, York, UK 